\title{
FORMAÇÃO DA COMUNIDADE CIENTÍFICA DE ENFERMAGEM NO BRASIL
}

\author{
Eliane Brandão Salles ${ }^{1}$, Ieda de Alencar Barreira ${ }^{2}$
}

\begin{abstract}
${ }^{1}$ Doutora em Enfermagem. Professor Adjunto da Escola de Enfermagem da Universidade Federal Fluminense. Rio de Janeiro, Brasil. E-mail: ebrandaosalles@yahoo.com.br

2 Doutora em Enfermagem. Professora do Programa de Pós-Graduação da Escola de Enfermagem Anna Nery da Universidade Federal do Rio de Janeiro. Pesquisadora CNPq. Rio de Janeiro, Brasil. E-mail: iedabarreira@openlink.com.br
\end{abstract}

RESUMO: Estudo do processo de cientifização da enfermagem brasileira, que comporta a formação de grupos geracionais portadores do habitus científico, e a construção do campo científico da Enfermagem. Tem por objetivos caracterizar as gerações de enfermeiras pesquisadoras no Brasil e discutir a dinâmica do campo científico de enfermagem. Adota como referencial teórico o conceito de geração de Karl Mannhein e Sirinelli; conceitos de habitus e campo, de Pierre Bourdieu. Estudo com abordagem histórico-social. Como resultados foram classificadas cinco gerações de enfermeiras pesquisadoras brasileiras: as pioneiras, dos anos 1950; as autodidatas, dos anos 1960; as acadêmicas, dos anos 1970 e 1980; a geração da produção sistemática e coletiva iniciada na virada dos anos 1980/1990; a geração das pesquisadoras com produção científica internacional surgida em meados da década de 1990. Conclui-se que o processo de cientifização ocorreu segundo as características geracionais da comunidade científica, e as lutas simbólicas ocorridas no campo da enfermagem brasileira.

DESCRITORES: História da Enfermagem. Enfermagem. Pesquisadores.

\section{THE DEVELOPMENT OF NURSING SCIENTIFIC COMMUNITY IN BRAZIL}

\begin{abstract}
This is a study of the scientific process of Brazilian nursing, which includes the formation of generational groups holding the scientific habitus, and the construction of the nursing scientific field. It aims to characterize the generations of Brazilian nursing researchers and to discuss the dynamics of the nursing scientific field. Karl Mannhein`s e Sirinelli`s concepts of generation, and Pierre Bourdieu's concepts of habitus and field are adopted as theoretical references. This is a social-historical study. The results were classified into five generations of Brazilian nurse researchers: the "pioneers", from the 1950`s; the "self-taught", from the 1960`s; the "academics", from the 1970`s and 1980`s; the "systematic and collective production" generation initiated at the end of the 1980`s and beginning of the 1990's; and finally, the generation of "researchers with international scientific production" which appeared in the mid 1990`s. We conclude that the process of making Brazilian nursing scientific occurred according to the generational characteristics of the scientific community and on the symbolic struggles which occurred in the field of Brazilian nursing.
\end{abstract}

DESCRIPTORS: History of nursing. Nursing. Researches.

\section{FORMACIÓN DE LA COMUNIDAD CIENTÍFICA DE ENFERMERÍA EN BRASIL}

RESUMEN: Estudio del proceso de ciencia de la enfermería brasileña que abarca la formación de grupos generacionales portadores del habitus científico y la construcción del campo científico de la enfermería. Tuvo por objetivos caracterizar las generaciones de enfermeras investigadoras en Brasil y discutir la dinámica del campo científico de enfermería. Referencia teórico: concepto de generación de Karl Mannhein y Sirinelli, del habitus y de campo, de Pierre Bourdieu.. Investigacion com abordaje socio-historico. Como resultados se clasificaron cinco generaciones de enfermeras investigadoras brasileñas: las "pioneras", de los años 50; las "autodidactas", de los años 60; las "académicas", de los años 70 y 80; la generación de la "producción sistemática y colectiva", iniciada en la media de los años 80/90; la generación de las "investigadoras con producción científica internacional", surgida en mediados de la década de 90. Se concluyó que el proceso de ciencia ocurrió según las características generacionales de la comunidad científica y las luchas simbólicas ocurridas en el campo de la enfermería brasileña.

DESCRIPTORES: Historia de la Enfermería. Enfermería. Investigadores. 


\section{INTRODUÇÃO}

O presente estudo trata do processo de cientifização da Enfermagem brasileira, o qual comporta duas dimensões interrelacionadas, quais sejam: 1) a formação da comunidade científica de enfermagem no país, ou seja, de um grupo portador do habitus científico, cuja reprodução se dá pela sucessão de grupos geracionais, cada qual inserido em determinado tempo e espaço e que, pelos vínculos concretos que mantêm entre seus membros, apresentam similaridades quanto à sua formação e a produção científica, compartilhando um destino histórico e social comum; 2) a construção do campo científico da Enfermagem, isto é, o espaço onde se dão as lutas simbólicas por capital social, no caso, a legitimação da autoridade científica onde atua tal comunidade, a qual se orienta por um conjunto de valores e é detentora de uma prática científica sistematizada, dotada de regras próprias e modelos a seguir, e que engloba as instituições encarregadas da produção e da circulação dos bens científicos e da formação e circulação dos produtores desses bens, os pesquisadores.

Num esforço de visão retrospectiva vinculada ao presente, quando se escolheu o processo de cientifização da Enfermagem brasileira como objeto de investigação, julgou-se muito importante analisar a formação da comunidade científica através das enfermeiras pesquisadoras, como produziram suas pesquisas e como se formou seu habitus científico. É na identificação de suas experiências, relacionadas ao processo histórico e social e, portanto, no compartilhamento de seus esforços e produções que desenvolveram ações historicamente relevantes, as quais dão margem ao acabamento analítico do conceito de geração.

O segundo aspecto destacado no presente estudo refere-se à estruturação do campo científico da Enfermagem no contexto dos anos 1950 - 2010 e à sua dinâmica, que criou as condições para que se produzissem pesquisas como elementos essenciais ao processo de formação desse campo da enfermagem no Brasil.

Tomando-se como ponto de referência as contribuições de estudiosos, ${ }^{4}$ pode-se inferir que o campo científico engloba as instituições encarregadas da produção e circulação dos bens científicos e da formação e circulação dos produtores desses bens. De um modo geral, esse campo é um espaço de investigação e de formação de pesquisadores, através das instituições de ensino superior, universidades, institutos de pesquisa, associações de classe, que, conjugadas, constituem também espaço privilegiado de socialização do conhecimento.
O estudo do processo de cientifização da Enfermagem no Brasil pretende oferecer significativa contribuição à compreensão dos fatos políticos, sociais e do ambiente científico da época, os quais, certamente, interferiram nas tentativas, nos êxitos e dificuldades quanto à implantação de uma estrutura científica forte, ativa, continuada e sistemática, numa profissão ainda em desenvolvimento, sem tradição de pesquisa.

Este estudo, de natureza histórico-social, tem como objetivos caracterizar as gerações de enfermeiras pesquisadoras no Brasil e discutir a dinâmica do campo científico de Enfermagem, na segunda metade do século 20 e início do século 21 (1950-2010).

\section{REFERENCIAL TEÓRICO}

O estudo baseia-se no conceito de geração..$^{1-2}$ O fenômeno da geração, demarca-se por uma abordagem sociológica, ao pesquisar os processos sociais e as interações que estruturam a sucessão das gerações, com o objetivo de compreender as mudanças sociais. ${ }^{1}$ Com isso, contribui para que se descubra a existência das gerações efetivas, compatíveis com o ritmo de mudança social. Segundo essa abordagem, o fenômeno geral da situação social é caracterizado por uma situação comum de vários indivíduos numa estrutura social. Decorre dessa premissa que a geração é um tipo particular de situação social.

Assim, o "fenômeno social da 'geração' representa um tipo particular de identidade de situação, abrangendo 'grupos etários' relacionados, incrustados em um processo histórico-social" ${ }^{1: 73}$ A natureza da situação etária é determinada pelo modo como certos padrões de experiência e de pensamento tendem a ser trazidos à existência, pelos dados naturais da transição de uma para outra geração. Coerente com essa perspectiva teórica, afirma que "um estrato demográfico só se torna uma geração, quando adquire uma existência autônoma e uma identidade - ambas geralmente determinadas por um acontecimento inaugurador". 2:133

O estudo baseia-se ainda nos conceitos de habitus e de campo..$^{3-4}$ O habitus apresenta-se como social e individual e refere-se a um grupo ou classe como também ao indivíduo. Desta forma, "a história de um indivíduo se apresenta como uma variante estrutural do habitus de seu grupo, de sua classe, o seu estilo aparece como desvio codificado em relação ao estilo de uma época, de uma classe ou de um grupo social". ${ }^{3: 80-1}$ 
O campo científico é definido como um campo social, com suas relações de força e monopólios, suas lutas e estratégias, seus interesses e lucros, onde todas essas invariantes revestem formas específicas. ${ }^{4}$ Para tratar da estrutura e da dinâmica do campo científico da enfermagem, é necessário compreender a sua gênese e apreender a crença que o sustenta, o jogo de linguagem que nele se joga, as coisas matérias e simbólicas em jogo que nele se geram, ou seja, é explicar,tornar necessário, os atos dos produtores e as obras por eles produzidas. ${ }^{4}$

Acrescenta-se ainda que a ordem estabelecida no campo científico define a ciência oficial, como um "conjunto de recursos científicos herdados do passado que existem no estado objetivado sob forma de instrumentos, obras, instituições, e no estado incorporado sob forma de hábitos científicos". ${ }^{4: 137}$

Interessa estudar a configuração e origem do campo científico, as hierarquias e as lutas entre os agentes nesse campo, analisando de forma concreta as relações estabelecidas dialeticamente entre as estruturas e o habitus dos seus agentes. O campo científico é formado por instituições destinadas a formar pesquisadores e garantir a produção dos bens científicos de uma determinada área.

\section{METODOLOGIA}

Neste estudo, o processo de cientifização da Enfermagem brasileira foi enfocado numa perspectiva histórica-social, abordagem que prioriza a experiência humana e os comportamentos sociais e sua dimensão histórica. ${ }^{5}$

De forma específica, adota-se a geração como uma "estrutura" que na análise histórica é levada em consideração, e que contribui para reabilitar o acontecimento. A geração existe, no território do historiador, como objeto de história e como instrumento de análise. Para o autor, "as gerações criadas ou modeladas por um acontecimento inaugurador, são geradoras de estruturas, ao invés de serem apenas a espuma vaga formada pelas estruturas sócio-econômicas". 2:132

A partir daí, procedeu-se a seleção, análise e interpretação de fontes primárias referentes ao período estudado. Foram utilizadas fontes primárias do Acervo de Depoimentos do Centro de Estudos e Pesquisas (CEPEn) da Associação Brasileira de Enfermagem (ABEn), depoimentos de história de vida associativa das enfermeiras que participaram das atividades desenvolvidas pela ABEn nos seus primeiros cinqüenta anos (1926-1976). Foram ainda, utilizadas fontes primárias do Centro de Documentação da Escola de Enfermagem Anna Nery (EEAN) da Universidade Federal do Rio de Janeiro (UFRJ), como documentos escritos de caráter oficial- atas e relatórios sobre os concursos de livre docente, anos 1968, 1975 e 1977, realizados na EEAN/UFRJ; Série Memoriais e Currículos, referentes aos concursos de livre docente anos 1968, 1975 e 1977. As fontes documentais predominantes foram: dispositivos legais referentes à enfermagem; documentos internamente produzidos na ABEn, tais como: planos e projetos, atas, regulamentos, ofícios, relatórios, recomendações e cartas.

As fontes secundárias referem-se a artigos, livros, teses e dissertações sobre a história da enfermagem e o contexto social da época abrangida pelo estudo.

\section{RESULTADOS E DISCUSSÃO}

Tomando-se o critério geracional como ponto de referência analítica, verifica-se que pesquisadores enfermeiros podem ser distribuídos em cinco gerações, cada qual com características peculiares ao seu tempo. Assim, de acordo com esse critério ${ }^{2}$ um acontecimento inaugurador ou assinalador marca a identidade de uma geração.

No Brasil identificamos cinco gerações de pesquisadores enfermeiros, a saber:

1) as pioneiras: anos 1950/1960;

2) as autodidatas: anos 1960/1970;

3) as acadêmicas: anos 1970/1980;

4) grupos de pesquisa com produção científica sistemática e coletiva: anos 1990;

5) pesquisadores líderes de grupos de pesquisa com produção científica internacional: anos 2000 do século 21.

\section{Primeira geração: as pioneiras}

A geração das pioneiras, que despontou nos anos 50, constitui o primeiro grupo de enfermeiras brasileiras, cuja produção merece destaque, sendo portanto consideradas as precursoras dos estudos científicos na área de enfermagem em nosso país.

A primeira tentativa bem sucedida de um estudo de âmbito nacional, para conhecer o quantitativo da enfermagem no país ocorreu em 1950. Denominado - Levantamento Censitário, ${ }^{6}$ contou com a colaboração da Associação Brasileira de Enfermeiras Diplomadas (ABED) e de órgãos do 
Ministério da Saúde (MS). Dirigiu esse trabalho a enfermeira Isaura Barbosa Lima, chefe da Seção de Enfermagem da Divisão de Organização Sanitária, e representante da ABED, que formou a Comissão do Censo composta pelas enfermeiras Waleska Paixão, Clara Curtis, Haydée Guanais Dourado, Rosa de Paula Barbosa e Mirabel Smith Ferreira Jorge.

O relatório final deste estudo foi divulgado no mesmo ano, no IV Congresso Nacional de Enfermagem, sendo aprovadas as seguintes recomendações: a criação de seção de enfermagem no Serviço Nacional de Fiscalização da Medicina, com o intuito de manter o cadastramento atualizado dos enfermeiros diplomados no Brasil, e a realização do Levantamento Censitário a cada cinco anos, abrangendo também outras categorias ocupacionais. $^{7}$

Em fevereiro de 1950, a $1^{\text {a }}$ Reunião de Peritos em Enfermagem da Organização Mundial de Saúde (OMS), realizada em Genebra, recomendou aos países membros que realizassem um Estudo dos Recursos de Enfermagem, com a assessoria da OMS. Neste sentido, foi organizado um - Guia para Estudos Nacionais de Recursos de Enfermagem. ${ }^{8}$

A comunidade brasileira de enfermagem mobilizou-se durante cinco anos em torno desse estudo, culminando com a realização da pesquisa institucional, em todo o país, denominado Levantamento de Recursos e Necessidades de Enfermagem no Brasil (LRNEB), realizada entre 1956-1958, pela ABEn, com apoio da Fundação Rockfeller-EUA.

O estudo da geração de pesquisadoras pioneiras na enfermagem, ${ }^{9}$ considerou como fato assinalador dessa geração esta primeira pesquisa em enfermagem, de âmbito nacional, o LRNEB.

Foram consideradas como representantes dessa geração, as enfermeiras Maria Rosa Souza Pinheiro, Maria de Lourdes Verderese, Haydée Guanais Dourado e Olga Verderese, responsáveis por esta pesquisa. No referido trabalho, a autora, analisa a formação do habitus científico e a trajetória profissional dessas enfermeiras e discute a dinâmica do campo científico da enfermagem, durante a produção do citado Levantamento. O empenho das pesquisadoras da geração pioneira, no desenvolvimento do LRNEB e o resultado do seu trabalho foram elementos essenciais na constituição inicial da comunidade científica de enfermagem na sociedade brasileira. A ABEn funcionou no campo científico da enfermagem brasileira, como instituição capaz de assegurar a produção de pesquisas na área de enfermagem, como também a circulação de informação entre os pesquisadores da área.

\section{Segunda geração: as autodidatas}

A geração das autodidatas, que surgiu nos anos 1960/1970, corresponde a um grupo mais numeroso, teve como fato assinalador dois fenômenos importantes na educação nacional - a abertura de concursos para o provimento de cargos de professor catedrático e de concursos para a obtenção de títulos de doutor e de livre-docente, na Universidade de São Paulo (USP) e na UFRJ, no Brasil.

Glete de Alcântara é autora da primeira tese de cátedra, intitulada - A enfermagem moderna como categoria profissional: obstáculos à sua expansão na sociedade brasileira, 1966, apresentada à Escola de Enfermagem de Ribeirão Preto da USP.

Com a Reforma Universitária de 1968, a universidade brasileira sofreu uma reforma administrativa que implantou os institutos centralizados e os departamentos como unidades administrativas com lotação de pessoal e de recursos materiais próprios, que congregavam um conjunto de disciplinas afins, correspondentes a determinadas áreas de conhecimento. A Reforma Universitária organiza a carreira docente, as cátedras foram extintas sendo substituídas pelo professor titular, com exigência de titulação de mestre, doutor ou livre-docente. As escolas de enfermagem deveriam atender a exigência de qualificação do corpo docente através da obtenção dos referidos títulos. Determinando que algumas escolas de enfermagem acelerassem o processo de implantação de seus cursos de pós-graduação stricto sensu.

A maioria dos docentes universitários não tinha formação acadêmica em nível de mestrado. Assim, a partir de 1968 ocorre a abertura de concursos para a obtenção de títulos de doutor e de livre-docente, na EEAN/UFRJ.

A prova de habilitação à livre-docência a que se refere a Lei $\mathrm{N}^{0} 5802$, de 11 de setembro de 1972, compreendia: julgamento de curriculum vitae; julgamento de tese ou dissertação e respectiva defesa; prova escrita; prova didática e, quando couber prova prática. ${ }^{10}$

Com relação aos concursos para a obtenção de títulos de doutor e de livre-docente na área de enfermagem, no que tange ao julgamento de tese e dissertações, destacam-se as dificuldades apontadas pelas docentes uma vez que a maioria não possuía formação acadêmica em nível de 
mestrado, portanto, na elaboração de pesquisas. Da produção de teses e dissertações desenvolvidas pelas enfermeiras que realizaram os respectivos concursos, representantes dessa geração, podemos dizer que contribuiu para elevar o numero de produções científicas da área de enfermagem. Estudos apontam a mobilização dos enfermeiros em torno destes concursos, os esforços empreendidos na realização das pesquisas e uma análise das temáticas desenvolvidas por essas enfermeiras. ${ }^{11-12}$

\section{Terceira geração: as acadêmicas}

A geração das acadêmicas aparece nos anos 1970, e congrega um grupo mais recente de enfermeiras pesquisadoras, tendo como fato assinalador a criação dos cursos de Mestrado, e consolida-se, na década de 1980, com a implantação do curso de Doutorado no país.

A Reforma Universitária de 1968, a institucionalização da pós-graduação e o incentivo formal à pesquisa continham como objetivos: formar professores para os cursos de graduação; preparar pessoal para atuar junto aos órgãos públicos e privados; e apoiar os estudos e pesquisas em desenvolvimento no país.

Até a implantação da reforma universitária, o número de universidades no Brasil (em todas as áreas) que ofereciam cursos de pós-graduação stricto sensu era pequeno. O preparo dos poucos docentes em cursos desse nível era feito em outros países, principalmente nos Estados Unidos, com financiamento de fundações estrangeiras. A pesquisa científica ficava restrita a poucos institutos de pesquisa como: O Instituto de Manguinhos-RJ, e Butantã-SP; o Instituto de Biofísica da UFRJ; do Centro Brasileiro de Pesquisas Físicas; Instituto de Física Teórica e de Energia Atômica, ambos da USP e Instituto de Matemática Pura e Aplicada. ${ }^{13}$

A organização e o desenvolvimento da pesquisa em enfermagem no Brasil são recentes e estão diretamente ligados a pós-graduação stricto sensu. A pesquisa na Enfermagem só tomou vulto a partir do seu ingresso no Sistema Nacional de Pós-Graduação, iniciando o seu primeiro curso de Mestrado em 1972, na EEAN/UFRJ.

A criação do mestrado trouxe visibilidade para a enfermagem nos órgãos de fomento no país. O Conselho Nacional de Desenvolvimento Científico e Tecnológico (CNPq), órgão governamental de financiamento, passa a incluir um representante da área de Enfermagem, no Comitê Assessor Multidisciplinar deSaúde, com o objetivo de prestar assessoria ao $\mathrm{CNPq}$ na avaliação de projetos e programas, na formulação de políticas em assuntos da sua área de competência e na apreciação das solicitações de apoio à pesquisa e a formação de recursos humanos.

No $2^{\circ}$ Seminário Nacional sobre Ensino de Pós-Graduação e Pesquisa em Enfermagem promovido pelo CNPq/ABEn, em Brasília, 1982, foram definidas três grandes áreas de pesquisa, a saber: Profissional; Assistencial; e Estrutura, organização e funcionamento das Instituições que, no conjunto totalizavam 11 linhas de pesquisa. A linha de pesquisa foi definida como uma proposta de investigação sobre um ou vários temas correlacionados, contínuo ao longo do tempo, em questões e problemas relativos à necessidade da população, realizada de modo progressivo e em condições para imediato engajamento de novos pesquisadores. ${ }^{14}$

Segundo avaliação da produção nessa época, a pesquisa em enfermagem vai se distanciando das fundamentações teóricas da biologia e se aproximando dos referenciais da ciências humanas e sociais. ${ }^{15}$

Em 1981 foi criado o primeiro curso de Doutorado em Enfermagem no Brasil e na América Latina, na Escola de Enfermagem da USP, em conjunto com a Escola de Enfermagem de Ribeirão Preto (EERP) da USP (doutorado inter-unidades). A produção científica de Enfermagem no Brasil teve como ponto alto a implantação desse curso, uma vez que o doutorado constituiu na culminância do processo de implantação da preparação formal de pesquisadores em enfermagem no país. ${ }^{14}$

Outras instituições criaram os seus cursos de mestrado e doutorado, a fim de qualificar o seu corpo docente e consolidar a pesquisa.

Os esforços voltados para o desenvolvimento de uma atividade de pesquisa acadêmica, sistemática e regular, resultaram no aumento quantitativo da produção científica de enfermagem. No entanto, essa produção apresentava enorme dispersão temática, com forte influência da pesquisa de enfermagem norte-americana, cujo enfoque teórico-metodológico era de cunho positivista e quantitativo, seguindo o critério de divisão segundo as especialidades médicas. Nesta fase a produção científica ainda era incipiente, constituída em grande parte por trabalhos acadêmicos, desenvolvidos por um pesquisador-orientador de forma individual, deixando de contribuir para a consolidação de estudos e linhas de pesquisa na área de enfermagem. ${ }^{12}$ 


\section{Quarta geração: grupos de pesquisa com} produção sistemática e coletiva

A quarta geração de pesquisadores da enfermagem, desenvolveu-se a partir de 1990, tendo como fato assinalador a formação de grupos de pesquisa com produção sistemática e coletiva na área de enfermagem em nosso país.

A preocupação com a dispersão temática da produção científica da área, muitas vezes realizadas por um único pesquisador, cuja produção não apresentava características de continuidade e consistência, levou a que na reunião nacional dos Programas de Pós-graduação em Enfermagem, promovida pela Coordenação de Aperfeiçoamento de Pessoal do Ensino Superior (CAPES), CNPq e ABEn, ao final de 1991, fosse conceituada linha de pesquisa como uma proposta coletiva de trabalho, unificando a produção do conhecimento e direcionando uma atividade continuada de pesquisa de um conjunto de temas correlacionados, com a finalidade de conhecer e responder às necessidades da vida e da saúde dos indivíduos, de elaborar projetos para o futuro e de promover o desenvolvimento da profissão. ${ }^{17}$

Tal conceituação representa um avanço, tanto no que se refere à abrangência como ao entendimento do processo de geração de conhecimento.

Uma linha de pesquisa consolidada apresenta-se sob a forma de uma sucessão de projetos, desenvolvidos ao longo do tempo, que se constitui para atender a uma necessidade social, mediante um trabalho coletivo, institucionalizado e apoiado por uma ou mais agências de fomento, de um grupo de pessoas com vários níveis de qualificação e de experiência, que se organiza em torno de certas questões de determinada área do saber. No entanto, ao tempo em que produz conhecimento e participa do debate da comunidade científica, tal grupo se reproduz e se renova, pela reconsideração permanente do conhecimento produzido, pelas mudanças acarretadas pelas necessidades de pesquisa e por contingências de seus participantes. ${ }^{18}$

A fidelidade a uma linha de pesquisa permite que, cada vez mais o professor/orientador fale e trate daquilo que melhor conhece e, em assim sendo, conheça cada vez mais o seu objeto de estudo. Ao mesmo tempo, a definição da linha de pesquisa dos professores/orientadores permite aos candidatos ao curso uma escolha mais esclarecida, tanto do orientador quanto do tema escolhido para a tese, e até mesmo do curso onde irá postular uma vaga. Por sua vez, o processo de elaboração de teses, uma vez ocorrendo no interior de um grupo de pesquisa, adquire mais consistência, podendo tornar a atividade de orientação mais proveitosa e menos desgastante para professores e alunos. Além do clima estimulante, devido ao constante intercâmbio de informações, conhecimentos e idéias, adquire-se a consciência do valor da crítica, enquanto atividade imprescindível à produção do conhecimento. ${ }^{19}$

O impacto da produção científica desta geração se fez no incremento do número de publicações, na sua inclusão em bibliografias recomendadas nos Cursos de Enfermagem e na citação, em publicações de alta qualidade, do artigo ou obra.

As condições de possibilidade da consolidação de uma linha de pesquisa se darão conjuntamente com as lutas pela formação da comunidade científica da Enfermagem brasileira e pela constituição de seus espaços. Isto vem ocorrendo por meio da formação grupos de pesquisa, que vêm desenvolvendo suas linhas de pesquisa e formando gerações de pesquisadores que dêem continuidade e expandam suas áreas de estudos.

As antigas áreas e linhas de pesquisa, definidas em 1982, no $2^{\circ}$ Seminário Nacional de Pesquisa em Enfermagem (SENPE), foram re-estudadas a partir de 1998, em fóruns de discussões dos Programas de Pós-Graduação (PPG), culminando com o $10^{\circ}$ SENPE e o 51 Congresso Brasileiro de Enfermagem e o $10^{\circ}$ Congresso Panamericano de Enfermería, realizados em 1999, dando origem as áreas e respectivas linhas, especificadas no Quadro 1. ${ }^{20}$

A pesquisa que originalmente começou junto aos PPGs, cresceu muito visto a sua utilização na prática e no ensino de graduação. Deixa de ser uma atividade individual, passando a ser desenvolvida coletivamente, através da articulação de pesquisadores nos grupos e núcleos de pesquisa, atendendo assim à política dos órgãos de fomento no país. Esses núcleos de estudos, grupos de pesquisa são liderados por um pesquisador-líder, e têm gerado saberes articulados a partir da junção de pesquisadores experientes, enfermeiros, docentes e discentes de graduação e pós-graduação. Panorama dos Grupos de Pesquisa em Enfermagem registrados no Diretório do CNPq apontam a existência de 301 grupos, articulados aos 30 PPGs em Enfermagem existentes no país em 2007. ${ }^{21}$ 
Quadro 1 - Áreas e respectivas linhas de pesquisa da enfermagem no ano de 1999

\begin{tabular}{|l|l|l|}
\hline \multicolumn{2}{|c|}{ Áreas e linhas de pesquisa } \\
\hline Profissional & Assistencial & Organizacional \\
\hline $\begin{array}{l}\text { 1.Fundamentos do cuidar na en- } \\
\text { fermagem }\end{array}$ & $\begin{array}{l}\text { 1.Processo de cuidar em en- } \\
\text { fermagem (criança, adoles- } \\
\text { cente, mulher, adulto, idoso) }\end{array}$ & 1.Políticas e práticas em saúde e enfermagem \\
\hline $\begin{array}{l}\text { 2.Concepções teórico-filosóficas } \\
\text { de Enfermagem }\end{array}$ & $\begin{array}{l}\text { 2.Cuidar em enfermagem no } \\
\text { processo saúde-doença }\end{array}$ & 2.Políticas e práticas de educação e enfermagem \\
\hline 3.Tecnologias de enfermagem & $\begin{array}{l}\text { 3.Determinantes de qualidade } \\
\text { de vida e saúde-doença }\end{array}$ & 3. Produção em saúde e trabalho na enfermagem \\
\hline 4.Ética na saúde e enfermagem & & $\begin{array}{l}\text { 4.Gerenciamento dos serviços de saúde e de en- } \\
\text { fermagem }\end{array}$ \\
\hline 5.História da enfermagem & 5.Informação/comunicação e enfermagem \\
\hline
\end{tabular}

Liderança em pesquisa é uma qualidade esperada do enfermeiro com preparo em nível de doutorado, o qual requer no mínimo três competências: integrar conhecimento científico com outras fontes para avançar a prática de enfermagem; desenvolver explicações teóricas sobre fenômenos clínicos de enfermagem através de pesquisa empírica e, desenvolver e aplicar métodos científicos para testar, refinar e ampliar o corpo de conhecimento da área. No entanto, liderança em pesquisa de enfermagem ultrapassa essas competências. Inovação do ato de produzir e disseminar resultado de pesquisa exigem outras competências que incluem iniciativas individuais e coletivas com a nucleação de pesquisadores em projetos de co-criação. Tal corporação que se forma na criação do conhecimento, vai além da formação de equipes de pesquisadores, indo em direção ao esforço a potencializar o papel do empreendedor. O processo empreendedor envolve as seguintes etapas: identificação e avaliação de oportunidades; desenvolvimento do plano a ser implementado; determinação e captação de recursos necessários e gerenciamento do projeto. Esta liderança focaliza o financiamento como um meio dinamizador que incentiva e propicia a produção e a disseminação do conhecimento. As reflexões sobre as competências requeridas para a liderança em pesquisa, enfatizando as estratégias de captação de recursos para a produção de pesquisa na enfermagem junto ao CNPq. ${ }^{22}$

$\mathrm{O} \mathrm{CNPq}$ vem delineando tendências que apontam para estudos que valorizam a multidisciplinaridade e o pluralismo, tanto teórico quanto metodológico, na construção das linhas e áreas de pesquisa que conformam a produção científica por ele financiada. ${ }^{23}$

No Seminário - Desafios em Ciência e Tecnologia no Brasil, realizado em outubro de 1997, promovido pelo CNPq, recomendou-se que os projetos devem ser interdisciplinares, de abrangência regional e propiciar novos vínculos, nacionais e internacionais, para cooperação científica e intercâmbio de tecnologias. Os projetos devem ser multicêntricos e contemplar a pesquisa e o desenvolvimento tecnológico complementares, compartilhados nos grupos de pesquisa que, por sua vez, poderão ser vinculados a diversas instituições. ${ }^{23}$

Entre as prioridades de pesquisa da Agenda Nacional de Pesquisa em Saúde do MS do Brasil está a otimização de recursos destinados as atividades de fomento à pesquisa no país, de modo a que possam resultar em melhorias dos serviços e ações de saúde prestados no âmbito do SUS e, consequentemente, na melhoria dos níveis de saúde da população. Destaca-se as sub-agendas de prioridade de pesquisa em saúde, a saber: doenças transmissíveis; doenças não-transmissíveis; saúde mental; violência, acidentes e trauma; saúde da mulher; saúde da criança; saúde do idoso; saúde dos povos indígenas; fatores de risco e, epidemiologia. ${ }^{24}$ Comparando esses dados, se verifica que existe uma tendência dos órgãos de fomento a privilegiar os estudos condizentes com o estabelecido na agenda nacional.

A Enfermagem, enquanto componente da área de saúde, deve estar atenta à regra e aproximar-se desta política, visando à aprovação dos seus projetos. Diante da crescente demanda nos balcões dos órgãos de fomento, percebem-se iniciativas para se atender ao critério da interdisciplinaridade (envolvendo pesquisas e pesquisadores em rede). ${ }^{25}$

Acrescenta-se aos desafios impostos pelas mudanças constantes da política e da economia globalizada; a elitização do saber científico, onde as agências de fomento exigem cada vez mais um perfil de pesquisador altamente qualificado; as tecnologias de ponta; a absorção do produto no 
mercado que deve gerar recursos-econômicos e sociais - comprovados; a divulgação do saber em nível internacional.

Recente estudo ${ }^{26}$ aborda as prioridades de pesquisas propostas pelas agendas de organismos internacionais de saúde e da enfermagem, em diferentes continentes. Com relação a prioridades de pesquisa em enfermagem: os efeitos do sistema de reformas da saúde; a oferta e a procura da força de trabalho; condições de trabalho; delegação de cuidados; processo saúde-doença nas populações vulneráveis; ética; aspectos culturais dos cuidados no atendimento domiciliar; saúde ocupacional e controle da infecção. Apresenta reflexões sobre o processo de definição de prioridades na produção do conhecimento da Enfermagem de forma que atenda tanto às necessidades de fundamentação das disciplinas, quanto às necessidades de saúde das populações; assim como reflexões sobre a definição de temas de futuras pesquisas em enfermagem.

\section{Quinta geração: pesquisadores-líderes de grupos de pesquisa com produção científica internacional}

A mais nova geração de pesquisadores líderes de grupos de pesquisa com produção científica internacional tem como fato assinalador o movimento de internacionalização da produção científica, surgido em meados de 2000, através do intercâmbio dos PPGs com as universidades estrangeiras, do incremento de eventos científicos internacionais e de publicações de artigos em periódicos internacionais.

Dada a evolução da Enfermagem brasileira, verifica-se a expansão dos cursos de Pós-Graduação em Enfermagem no país. Novas linhas de pesquisa foram criadas, grupos de pesquisas consolidados e, a produção científica foi registrada no Diretório de Grupos de Pesquisa e Plataforma Lattes do CNPq. De outro modo, as revistas científicas de enfermagem, que são importantes veículos de divulgação dos bens científicos, apresentam um grande crescimento e desenvolvimento no Brasil. Um estudo ${ }^{27}$ aponta que havia também uma preocupação com a adequação das publicações às normas nacionais e internacionais de editoração, bem como a preocupação com os padrões de qualidade dos periódicos científicos. Esse movimento foi constatado pela instrumentalização dos editores, assessoria de especialistas, criação da Comissão Nacional de Editores Científicos de Revistas de Enfermagem pela ABEn, participação de editores brasileiros no Conselho Consultivo Ibero-americano de Revistas de Enfermería, coordenado pela Fundação Index de Enfermería da Espanha, atualização da Base de Dados de Enfermagem (BDENF) e a criação da Biblioteca Virtual de Saúde-Enfermagem - BIREME.

Com essa evolução, os periódicos de enfermagem foram sendo incluídos em importantes indexadores nacionais e internacionais a saber: International Nursing Index e MedLine, Cumulative Index to Nursing \& Allied Health Literature (CINAHL), Literatura Latinoamericana em Ciências da Saúde (LILACS), PsycINFO (Base de dados da American Psychological Association), CUIDEN (Base de dados da Fundacíon Index), CAB HEALTH, CAB ABSTRACTS, BDENF (Base de dados em Enfermagem), Coleção SciELO (Scientific Electronic Library Online) entre outros. ${ }^{28}$

Estudo realizado em 2004 aponta o fato de que as revistas de enfermagem editadas no Brasil não estão indexadas no ISI Database (Institute of Scientific Information) que elabora anualmente o Journal Citation Report (JCR), Social Sciences Editions e Sciences Editions, contendo os indicadores bibliométricos de repercussão das revistas (fator de impacto, índice de imediacidade que determina a rapidez com que um artigo é lido e citado, vida média das citações e a classificação no ranking mundial). ${ }^{27}$

No Brasil, o fator de impacto das publicações vem recebendo prioridade pela CAPES, agência que avalia os PPGs, e consequentemente pelas universidades e pelas agências de fomento, o que tem suscitado esforços para a internacionalização da produção científica brasileira.

As revistas editadas nos países em desenvolvimento assumem uma posição estratégica na veiculação da produção científica que é direcionada às prioridades nacionais, em coerência com as linhas e prioridades de pesquisa estabelecidas. No entanto essa produção pode não ser de interesse de revistas internacionais, em especial de origem anglo-saxônicas, que representam a maioria das revistas indexadas no ISI, o que constitui, além das exigências de publicação em inglês, barreiras para a internacionalização da produção científica da Enfermagem brasileira. ${ }^{27}$

Em coerência com esse pensamento ${ }^{29}$ destaca-se o fortalecimento das revistas científicas nacionais como uma condição sine qua non para o constante avanço da base de ciência e tecnologia no Brasil, sem o qual não conseguiremos a internacionalização do resultado de nossas pesquisas. 


\section{CONCLUSÃO}

Numa reflexão sobre a questão da formação do habitus científico, de interesse particular para esta pesquisa, os dados dão notícia do processo de criação de escolas de enfermagem e de seus cursos de pós-gradução, a qual é a instituição social que merece lugar expressivo na formação do habitus científico do enfermeiro, em nosso país. Nesse sentido, vale dizer que as Escolas de Enfermagem têm contribuído para a organização do campo científico nessa área do conhecimento, como espaço de formação e circulação de pesquisadores e bem como lugar privilegiado de produção e divulgação de pesquisas da área.

Quando se reflete sobre o domínio do campo científico, com relação aos pesquisadores em enfermagem, portanto da comunidade científica, pode-se dizer que o empenho e atuação das cinco gerações de pesquisadores, representadas neste estudo, foram elementos essenciais na constituição da comunidade científica de enfermagem na sociedade brasileira.

No que tange ao processo de cientifização da Enfermagem brasileira, pode-se dizer que ocorreu de diferentes modos, segundo as características geracionais apresentadas pela comunidade científica, e as lutas simbólicas ocorridas dentro e fora do campo da Enfermagem brasileira, a cada momento histórico.

Ao final destaca-se alguns desafios que os pesquisadores de enfermagem terão que percorrer, ou seja: atender a política do CNPq e dos órgãos de fomento a pesquisa visando ter os seus projetos aprovados; atender as prioridades de pesquisa das agendas nacionais bem como as necessidades de fundamentação da própria Enfermagem na produção do seu conhecimento; e impulsionar o processo de internacionalização da produção científica da Enfermagem brasileira através do fortalecimento das revistas científicas nacionais.

\section{REFERÊNCIAS}

1. Mannheim K. Sociologia. São Paulo (SP): Ática, 1982.

2. Sirinelli JF. La génération. In: Périodes; la construction du temps historique. Paris (FR): EHESS; 1991. p. 129-34.

3. Bourdieu P. O poder simbólico. Rio de Janeiro (RJ): Bertrand do Brasil; 1989.

4. Bourdieu P. O campo científico. In: Ortiz R, organizador. Bourdieu P. $2^{\mathrm{a}}$ ed. São Paulo (SP): Ática; 1994. p.122-55.
5. Burke P. Abertura: A nova história, seu passado e seu futuro. In: Burker P. A Escrita da Historia: novas perspectivas. São Paulo (SP): UNESP, 1992.

6. Lima IB. Aspectos da situação de enfermagem no Brasil. Rio de Janeiro (RJ): Ministério da Educação e Saúde; 1950.

7. Carvalho AC. Associação Brasileira de Enfermagem: 1926-1976-Documentário. Brasília (DF): ABEn; 1976.

8. Arnstein, MG. Guide for National Studies of Nursing Resources. World Health Organization, Genebra (CH); 1953.

9. Brandão EM. A formação do campo científico de enfermagem no Brasil: sociologia da geração de pesquisadoras pioneiras-1935-1958 [tese]. Rio de Janeiro (RJ): Universidade Federal do Rio de Janeiro. Escola de Enfermagem Anna Nery; 1999.

10. Ministério da Saúde (BR). Enfermagem, Legislação e Assuntos correlatos. $3^{\text {a }}$ edição, Rio de Janeiro (RJ): Ministério da Saúde/Fundação Serviços de Saúde Pública; 1974.

11. Salles EB. Perfil e história de uma geração de pesquisadoras da enfermagem, na década de 60 e 70, no Brasil, denominada de autodidatas. In: Anais do I Simpósio Ibero-Americano de História da Enfermagem, 2007 Out 29-31; São Paulo, Brasil. São Paulo: Universidade de São Paulo Escola de Enfermagem da USP (SP); 2007. p. 314.

12. Martins ALT, Barreira IA. Concursos de LivreDocência na Escola de Enfermagem Anna Nery: estratégia de qualificação de professores. In: Anais da $11^{\mathrm{a}}$ Jornada Nacional de História da Enfermagem; Rio de janeiro, 2008 Mai 12-15; Rio de Janeiro (RJ): Escola de Enfermagem Anna Nery, Universidade Federal do Rio de Janeiro; 2008. p.240.

13. Baptista SS.Trajetória das escolas de enfermagem na sociedade brasileira. Esc Anna Nery Rev Enferm. 1997 Dez; 1(2):84-105

14. Nogueira M.J.C. Pesquisa em Enfermagem no BrasilRetrospectiva Histórica. In:Seminário Nacional Sobre Ensino de Pós-graduação e Pesquisa em Enfermagem, 2, Brasília,1982. Avaliação e Perspectivas. Relatório. Brasília: CNPq/ ABEn;1982.

15. Almeida MCP, Murakava T, Lima MADS. A pesquisa no ensino de pós-graduação em enfermagem stricto sensu (tema oficial). In: Anais do $8^{\circ}$ Seminário Nacional de Pesquisa em Enfermagem, Ribeirão Preto, 1995 Out 29-31; Ribeirão Preto (SP): ABEn / FAPESP; 1995. p.16-32.

16. Barreira IA, Baptista SS. Nexos entre a pesquisa em história da enfermagem e o processo de cientifização da profissão. In: Anais do $51^{\circ}$ Congresso Brasileiro de Enfermagem; 1999 Out 2-7; Florianópolis, Brasil. Florianópolis (SC): ABEn; 2000. p.295-311.

17. Conselho Nacional de Desenvolvimento Científico e Tecnológico. Reunião Nacional sobre os programas de pós-graduação stricto sensu da área da 
enfermagem. Relatório Final. Brasília (DF): CAPES/ CNPq/ABEn; 1991.

18. Barreira IA, Baptista, SS. O processo de construção de uma linha de pesquisa em história da enfermagem brasileira: contribuição, perspectivas e desafios. Colóquio panamericano de Investigação em Enfermagem. Ribeirão Preto; 1998. p. 270.

19. Barreira IA. A pesquisa no cotidiano da enfermagem. In: Anais do $8^{\circ}$ Seminário Nacional de Pesquisa em Enfermagem. RibeirãoPreto, 1995Out 29-31; Ribeirão Preto (SP): ABEn /FAPESP; 1995. p.93-100.

20. Carvalho V. Linhas de pesquisa e prioridades de enfermagem: proposta com distinção gnoseológica para o agrupamento da produção científica de pósgraduação em enfermagem. Esc Anna Nery Rev Enferm. 2002 Abr; 6(1):145-54.

21. Padilha MICS, Kletenberg DF, Gregório VRP, Borges MB, Borenstein MS. A produção de pesquisa histórica vinculada aos programas de pós-graduação no Brasil, 1972 a 2004. Texto Contexto Enferm. 2007 Out-Dez; 16(4):671-9.

22. Mendes IAC, Trevizan MA, Leite JL, Erdman AL. Financiamento como meio dinamizador da produção e divulgação de conhecimento. In: Anais do $56^{\circ}$ Congresso Brasileiro de Enfermagem; 2004
Out 24-29; Gramado (RS), Brasil. Brasília (DF): ABEn; 2005. p.215.

23. Conselho Nacional de Desenvolvimento Científico e Tecnológico. Desafios em ciência e tecnologia no Brasil. Brasília (DF): CNPq; 1998.

24. Guimarães R. Pesquisa em saúde no Brasil: contexto e desafios. Rev Saúde Pública. 2006 Ago; 40(1):3-10.

25. Leite JL, Mendes IAC. Pesquisa em enfermagem e seu espaço no CNPq. Esc Anna Nery Rev Enferm. 2000 Dez; 4(3):389-94.

26. Agudelo MCC. Trends and priorities in nursing research. Rev Latino-am Enfermagem. 2004 Jul-Ago; 12(4):583-8.

27. Marziale MHP. A internacionalização da produção científica: um grande desafio para a enfermagem brasileira. Rev Latino-am Enfermagem. 2004 SetOut; 12(5):701.

28. Marziale MHP, Mendes IAC. O fator de impacto das publicações científicas. Rev Latino-am Enfermagem. 2002 Jul-Ago; 10(4):466.

29. Coimbra CEA. Produção científica e impacto em saúde coletiva. Cad Saúde Pública. 2004 Jul-Ago.; 20(4):878-9. 